\title{
EDITORIAL
}

\section{The milky (path)way of proteinosis: has the time come?}

\author{
M. Luisetti
}

A

fter having read the paper by BoRIE et al. [1] in this issue of European Respiratory Review, I decided not to write a classic scientific editorial.

It is often difficult to write an editorial comment for a review article, and in this case even more so since the paper by BORIE et al. [1] is one of the most comprehensive and up-to-date reviews on pulmonary alveolar proteinosis (PAP) since the milestone article of SEYMOUR and PresNeILl [2]. What could I add or how would I comment on the achievement that lung biopsy is now no longer required to diagnose typical forms of autoimmune PAP? Or that the passive transfer of human granulocyte-macrophage colony-stimulating factor (GM-CSF) autoantibodies (GMAbs) to monkeys reproduces features typical of PAP, thus, supporting the pathogenic role of GMAbs [3]? Or that several surfactant-associated genes and proteins may be involved not only in proteinosis, but also in other forms of interstitial lung diseases [4]?

Beyond the intrinsic value of the scientific information, the review by BoRIE et al. [1] also has the added value of being readable from different perspectives. On the one hand, inclusion of PAP in a series of papers covering rare respiratory diseases contributes greatly to increased awareness about this disorder. In fact PAP, probably because of its almost negligible prevalence of 0.1 per 100,000 persons [5], usually ranks at the very bottom of the list of rare respiratory disease. As a result, many general practitioners and a number of pulmonologists are only vaguely, or not, familiar with the term proteinosis. The really bad news is that this term is also obscure to some health professionals who unknowingly neglect PAP in ministry lists of rare disease [6]. Although discouraging experience with $\alpha_{1}$-antitrypsin deficiency tells us that, despite intensive dissemination of information among caregivers, a delay in diagnosis and the number of physicians seen before diagnosis have not been reduced [7], there are only a few alternatives to increase awareness about a rare condition. On the other hand, in my experience, after many years of giving presentations on PAP at national and regional Italian pneumology conferences and hours of discussions with colleagues, more and more PAP patients are now attracted to the centre in Pavia, Italy. This is another winning strategy for a rare disease: to establish a reference centre where patients may receive the highest

Dept of Blood, Lung, Heart Disease, Pneumology Section, University of Pavia, IRCCS San Matteo Hospital Foundation, Pavia, Italy.

CORRESPONDENCE: M. Luisetti, SC Pneumologia, Fondazione IRCCS Policlinico San Matteo, Università di Pavia, Piazza Golgi 1, 27100 Pavia, Italy. E-mail: m.luisetti@smatteo.pv.it

PROVENANCE: Submitted article, peer reviewed. standard of diagnosis and care, and contribute to the creation of a critical sample size to plan research and trials.

Another key aspect of the article by BoRIE et al. [1] is the careful description of the incredible advances achieved in our understanding of the biochemical, immunological and genetic bases of the disorder. Interestingly, whole lung lavage (WLL) as a therapeutic approach for PAP was established [8] well before we understood the intimate mechanisms of PAP pathogenesis and, at present, WLL is still the standard of care for this disorder [9]. When I first visited the monuments of ancient Egypt, a guide showed me how the vaults of many temples were blackened by bonfires lit by shepherds two centuries ago during the cold season. It is surprising that they used the temples, almost totally filled in by desert sand (fig. 1), as caves to shelter their sheep without imagining what historic wonders were hidden metres below, beneath sand accumulated over the centuries. When I reflect on the much more recent past, I realise that for many years we have lavaged PAP patients without imagining what complicated and sophisticated mechanisms lay beneath the milky fluid that filled the alveolar spaces of our patients. The Copernican revolution following the serendipitous discovery of the role of GM-CSF in the homeostasis of surfactant is probably one of the most exciting examples of scientific progress in the understanding of a disease and, hopefully, more physicians and scientists will be attracted by this rapidly growing field of research. Undoubtedly, PAP will benefit from the expanding number of funded research projects specifically directed towards this disorder.

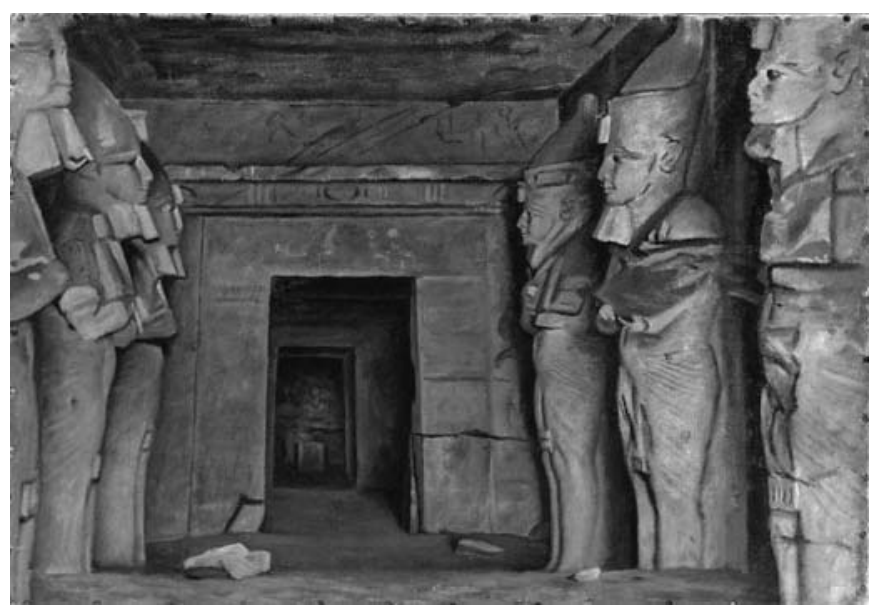

FIGURE 1. Interior of Temple of Rameses II at Abu Simbel, Egypt. Reproduced from [10] with permission from the publisher. 
Finally, from another angle, a specific position for rare diseases in the constellation of biomedical research is that they may help expand our understanding of complex pathways underlying common diseases [11] by behaving like Trojan horses. Thus, it is possible that in the near future many of the aspects that now appear specific to PAP may be applied to other conditions.

So, has the time come for PAP to be dragged out of the ghetto of neglected diseases? Probably not yet, or at least not completely. A positive sign of the increasing "relevance" of a given disease is indicated by the interest that has been shown by pharmaceutical companies. Other common diseases, such as chronic obstructive pulmonary disease, and rare diseases, such as $\alpha_{1}$-antitrypsin deficiency, idiopathic pulmonary fibrosis, sarcoidosis and pulmonary artery hypertension, have faced the same hurdles. So far the only randomised interventional trial in PAP has been funded by a special programme for independent research by the Italian Agency for Medicines (AIFA) [12,13], but now it seems we have reached the bases to build a co-operation among researchers, funding agencies and pharmaceutical companies [14-16] in promoting PAP clinical trials. This will definitely provide the attention that is due to this fascinating disorder.

\section{STATEMENT OF INTEREST}

None declared.

\section{ACKNOWLEDGEMENTS}

This work has been funded, in part, by the AIFA (Agenzia Italiana del Farmaco) project FARM7MCPK4 and E-Rare Joint call 2009 project "EuPAPNet".

\section{REFERENCES}

1 Borie R, Danel C, Debray M-P, et al. Pulmonary alveolar proteinosis. Eur Respir Rev 2011; 20: 98-107.

2 Seymour JF, Presneill JJ. Pulmonary alveolar proteinosis: progress in the first 44 years. Am J Respir Crit Care Med 2002; 166: 215-235.
3 Sakagami T, Beck D, Uchida K, et al. Patient-derived GM-CSF autoantibodies reproduce pulmonary alveolar proteinosis in nonHuman primates. Am J Respir Crit Care Med 2010; 182: 49-61.

4 Whitsett JA, Wert SE, Weaver TE. Alveolar surfactant homeostasis and the pathogenesis of pulmonary disease. Annu Rev Med 2010; 61: 105-119.

5 Orphanet Report Series. Rare Diseases Collection. Number 2. Prevalence of Rare Diseases: Bibliographic Data. November 2010. www.orpha.net/orphacom/cahiers/docs/GB/Prevalence_of_rare_ diseases_by_decreasing_prevalence_or_cases.pdf

6 Luisetti M, Campo I, Scabini R, et al. The problems of clinical trials and registries in rare diseases. Respir Med 2010; 104: Suppl. 1, S42-S44.

7 Campos MA, Wanner A, Zhang G, et al. Trend in diagnosis of symptomatic patients with alpha1-antitrypsin deficiency between 1968 and 2003. Chest 2005; 128: 1179-1186.

8 Ramirez J, Campbell GD. Pulmonary alveolar proteinosis. Endobronchial treatment. Ann Intern Med 1965; 63: 429-441.

9 Luisetti M, Trapnell BC. Pulmonary alveolar proteinosis. In: Schwarz MI, King TE Jr, eds. Interstitial Lung Disease. 5th Edn. Shelton, People's Medical Publishing House, 2011; pp. 1079-1093.

10 Longfellow EW. Interior of Temple of Rameses II at Abu Simbel. http:/ /commons.wikimedia.org/wiki/File: Interior_of_Temple_of_ Rameses_II_at_Abu_Simbel_byErnstLongfellow_MFABosten.png

11 Wanner A. COPD: new lessons from alpha1-antitrypsin deficiency. Chest 2009; 135: 1342-1344.

12 Luisetti M, Kadija Z, Mariani F, et al. Therapy options in pulmonary alveolar proteinosis. Ther Adv Respir Dis 2010; 4: 239-248.

13 Italian Medicines Agency (AIFA) Research \& Development Working Group. Feasibility and challenges of independent research on drugs: the Italian Medicines Agency (AIFA) experience. Eur J Clin Invest 2010; 40: 69-86.

14 Marshall I, Malur A, Arce S, et al. Rituximab and pulmonary alveolar proteinosis: what have we learned so far? Am J Respir Crit Care Med 2010; 181: A3994.

15 Borie R, Debray MP, Laine C, et al. Rituximab therapy in autoimmune pulmonary alveolar proteinosis. Eur Respir J 2009; 33: 1503-1506.

16 Luisetti M, Kroneberg P, Suzuki T, et al. Physical properties, lung deposition modeling, and bioactivity of recombinant GM-CSF aerosolised with a highly efficient nebulizer. Pulm Pharmacol Ther 2011; 24: 123-127. 